\title{
In Defence of the Shareability of Fregean Self-Thought
}

\author{
Víctor M. Verdejo ${ }^{1}$
}

Received: 1 October 2018 / Accepted: 27 November 2018 / Published online: 2 January 2019

(C) The Author(s) 2019, corrected publication 2019

\begin{abstract}
Consider the Unshareability View, namely, the view that first person thought or selfthought - thought as typically expressed via the first person pronoun — is not shareable from subject to subject. In this article, I (i) show that a significant number of Fregean and non-Fregean commentators of Frege have taken the Unshareability View to be the default Fregean position, (ii) rehearse Frege's chief claims about self-thought and suggest that their combination entails the Unshareability View only on the assumption that there is a one-to-one correspondence between way of thinking and thoughtindividuating cognitive value, (iii) outline an account of self-thought that rejects the assumption and keeps intact all of Frege's chief claims, and (iv) respond to a number of worries to the effect that this proposal yields undesirable results from the point of view of the individuation of self-thought at the level of cognitive value.
\end{abstract}

Keywords First person $\cdot$ Frege $\cdot$ Perspective $\cdot$ Cognitive value $\cdot$ Thought sharing

It seems platitudinous that people can, and generally, do share all sorts of thoughts. Consider the thought expressed by an utterance of "Fido is wounded". It is relatively unproblematic to make sense of the possibility of two people sharing that thought. They do so insofar as they entertain or have the capacity to entertain instances of the same relevant type of thought, namely, the "Fido is wounded"-type. In general, we might say, for two subjects $S$ and $S$ ' to share the thought that $p$ is for them to be able to think instances of the same p-type. ${ }^{1}$

Things are not so simple when considering what is usually called 'first person thought' or as I shall be using interchangeably, 'self-thought'. Self-thought is the

\footnotetext{
${ }^{1}$ Jerry Fodor takes this to be one of the non-negotiable constraints in the theory of concepts (cf. Fodor 1998, $28 \mathrm{ff}$ ). This initial characterisation is neutral on what exactly the notion of relevant type specified by a sentence type is, and in particular, on whether two distinct sentence types may pick out the same relevant thought type (see Verdejo 2018 for detailed discussion).
}

Víctor M. Verdejo

vmverdejo@gmail.com; victormverdejo@ub.edu

1 LOGOS Research Group/BIAP (Barcelona Institute of Analytic Philosophy), University of Barcelona, Room 4013, Montealegre 6-8, 4th floor, 08001 Barcelona, Spain 
type of thought one typically expresses via utterances of sentences containing the first person pronoun. ${ }^{2}$ A pervasive Frege-inspired tradition has assumed that selfthought is not shareable from subject to subject. Consider the sentence "I am wounded". On this view, no two people can think a thought of the same relevant type as the one expressible by means of an utterance of that sentence. We may call this the Unshareability View. For many years now, and as we shall see at length below (Section 1), it has seemed that the most reasonable way, if not the only way, of being a Fregean about first person thought or self-thought is by endorsing one version or other of the Unshareability View.

In this paper, I shall argue that the Unshareability View does not follow from any combination of Frege's chief claims about thought, and in particular, self-thought. This is so in spite of the fact that, remarkably enough, the available articulations of shareable Fregean self-thought — such as the ones owed to Bermúdez (2005, 2017), Harcourt (1999), Longworth (2013, 2014), May (2006a, b), or Rödl (2007)—do withdraw some or other of Frege's chief claims. The Unshareability View, I shall maintain, is based on an overlooked and controversial supplementation of the claims regarding what selfthought requires of a thinker. More precisely, I will suggest that, only by subscribing to a one-to-one correspondence between ways of thinking or modes of presentation and thought-individuating cognitive value, do those claims instil a commitment to the view that only one thinker can think a given self-thought.

The main point of concern in this piece is not exegetical. I set out rather to offer a full articulation of a theoretical possibility that has been so far understated in a Fregean milieu whether or not this was Gottlob Frege's own view on the matter-indeed, whether or not he had a view on the matter. All the same, a selective review of Frege's writings will help to substantiate some of the points to follow regarding the possibilities open when engaged in the individuation of shareable self-thought.

This article is structured as follows. In Section 1, I characterise in more detail the question of the shareability of self-thought as involving a requirement upon possession or thinkability and show that a significant number of Fregean and non-Fregean commentators of Frege have taken the Unshareability View to be the default Fregean position in this regard. I briefly rehearse, in Section 2, Frege's chief claims about self-thought, disclose what I call the Strict Fregean View, and suggest that the Unshareability View only follows from the Strict Fregean View under a narrow interpretation of Frege's theses about special modes of presentation, cognitive value, and reference determination. As an elaboration of this suggestion, I go on to outline, in Section 3, a perspective-based account of shareability that leaves intact Frege's key insights. The approach offered is, I shall suggest, more rightfully called 'Fregean' than alternative proposals which also defend the shareability of thought but forgo or blur one or more elements of the Strict Fregean View.

Even if it is true that we can make sense of an uncontrived Fregean framework where self-thought is shareable from subject to subject, one might still wonder whether this is a possibility worth pursuing in the light of other considerations. In Section 4, I

\footnotetext{
${ }^{2}$ Although they are perfect synonyms in this piece, I shall mostly be using 'self-thought' rather than 'first person thought' in order to duck the connotation that first person thought—or 'I'-thought as it is also sometimes called - must necessarily or essentially be restricted to uses of the first person pronoun. Since only I can use 'I' to express a self-thought that refers to myself, the connotation immediately suggests-in opposition to the view to be defended here - that only I can, properly speaking, think or entertain instances of the self-thought type that refers to myself.
} 
address in a preliminary way three worries about the proposed approach that would seem to arise more acutely in the context of a Fregean theory designed to individuate thoughts at the level of cognitive value: (i) the existence of iterated Frege's puzzles, (ii) a clash with the so-called Intuitive Criterion of Difference, and (iii) the possibility of explaining cognitive phenomena distinctively associated with self-thought. These considerations, I maintain, do not at first pass pose an insurmountable problem to the view that self-thought is shareable but, in fact, allow us to bring into focus unexplored aspects of Fregean self-thought such as its dynamic character and its public dimension in communication and action. Section 5 summarises the main points of the discussion.

\section{The Allure of the Special Self}

Suppose we hear somebody uttering "I am wounded" twice over from the room next door. Do these utterances express the same thought? One may give different answers depending on the situation at hand. Assuming that the utterances occur in a reasonably short interval, few will oppose a positive answer whenever both utterances come from one and the same speaker. And few will deny that the answer must lie in the negative if each utterance corresponds to a different speaker, that is to say, if each use of 'I' refers to a different subject. However, can we as hearers apprehend and think the very same thoughts expressed by those utterances? For many decades, it has seemed that Fregean theorists are by default committed to a negative answer to this last question.

As is known, the Fregean character of this commitment is instigated by the striking force of one central passage in Frege's writings famously occurring in Thoughts. The passage indisputably adverts to the existence of unsharable ways of thinking or modes of presentation:

...everyone is presented to himself in a special and primitive way, in which he is presented to no-one else. So, when Dr. Lauben has the thought that he was wounded, he will probably be basing it on this primitive way in which he is presented to himself. And only Dr. Lauben himself can grasp thoughts specified in this way." (Frege 1984, 359)

The thesis Frege puts forward here concerns specifically a type of thought, namely, the selfthought type. This is the type of thought one would typically, but perhaps not exclusively, express via utterances of sentences containing the first person pronoun. For instance, this is the type of thought expressed when Dr. Lauben utters the sentence "I am wounded". We may aseptically state the target thesis thus: There is a special and primitive way $w$ of thinking of a subject $x$ associated with uses of the first person pronoun such that only $x$ can have thoughts about $x$ on the basis of $w$. Leaving scope ambiguities to one side for the moment, the thesis is standardly taken to entail - in harmony with the view defended here - that there is a distinct, unshareable special and primitive way $w$ of thinking about $x$ for each and every $x$.

Now, Frege's oft-cited dictum in Thoughts has overwhelmingly been interpreted by commentators as being a necessity claim on the very possession or thinkability of the selfthought type. If we take special and primitive ways of thinking to display necessary conditions on the thinkability of self-thought, it just follows that self-thought must itself be special and primitive in ways that preclude shareability. On this account, it is because only 
Dr. Lauben can fulfil the thinkability conditions laid out by the special and primitive way of thinking about Dr. Lauben that only Dr. Lauben can think a self-thought that has Dr. Lauben as a reference. The thinkability condition for self-thought is, more precisely, that only the actual referents of self-thought - the self-referring subjects - can think instances of the same relevant type of self-thought. This is the Unshareability View as I will be considering it here.

In a very influential discussion of Frege's famous passage, John Perry braced the Unshareability View so understood as its natural interpretation. According to him, Frege claimed that "when one thinks about oneself, one grasps thoughts that others cannot grasp, that cannot be communicated" (Perry 1977, 474). Distinguished followers of Frege immediately agreed to John Perry's pioneering diagnosis in the late seventies. Gareth Evans is probably the most conspicuous example. Evans disputed many aspects of Perry's treatment of Frege but took the Unshareability View for granted and launched, in fact, one of its most vigorous defences. At the heart of this defence is the distinction between objectivity and shareability. On Evans's interpretation, it is the lack of objectivity but not shareability what would pose an unsurmountable problem to Frege's framework. "Since an unshareable thought can be perfectly objective - can exist and have a truth value independently of anyone's entertaining it", he observes, "there is no clash between what Frege says about 'I'thoughts and this, undeniably central, aspect of his philosophy" (Evans 1981, 313).

To the present day, other (neo-)Fregeans have followed in Evans's footsteps by proposing similar conceptual distinctions that would make the unshareability of self-thought more palatable and, in fact, entirely plausible. Michael Dummett, for instance, explicitly acquiesces that "without violating any essential principle of Frege's philosophy, [...] we may agree with Evans that 'there are thoughts which one can have only because one occupies a particular position in space or time, or because one is currently perceiving an object'; [...] [a]nd, by the same token, there are thoughts which only he can have, i.e. can think, who is the subject of them" (Dummett 1981, 122). In order to reconcile the Unshareability View with communication, however, Dummett draws the distinction between grasping and thinking a thought. On his propounded analysis, self-thoughts can be communicated because they can be grasped even if not actually thought by any thinker other than their bearers. Thus, "even if there are thoughts which only one person can think, or which only a person in some given situation can think, there is no need to conclude that there are thoughts that cannot be communicated" (Dummett 1981, ibid). Frege-inspired scholars such as Forbes (1987), Künne (1997), McDowell (1984), Noonan (1984) or Peacocke (1981, 1992, 2014), have advanced versions of this position. These are views in which even if self-thought is thinkable by at most one person, it is nonetheless graspable or knowable by others in ways that preserve the objectivity and communicability of thought. ${ }^{3}$

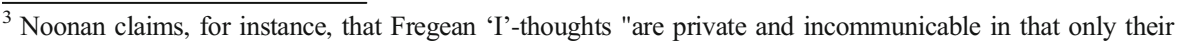
subject can think them; but other people can know exactly what thoughts he is thinking when he does so" (Noonan 1984, 216, emphasis his). Similarly, McDowell accepts "'I'-thoughts that only I can entertain" but observes that "such thoughts can figure in mutual understanding" (McDowell 1984, 290). Peacocke points out that "[...] you cannot judge what another does when he judges the first-person content 'I am hungry" " but, nonetheless, "you can still know what he judges, even if you cannot judge it yourself" (Peacocke 1992, 221). Forbes observes that "Frege's difficulty here [with the private sense of 'I'] is generated by the [disputable] assumption that communication of a thought requires the hearer to grasp it in a way which would allow him to go on to employ its constituents in thoughts of his own" (Forbes 1987, 20). For Künne, self-thoughts (or egopropositions) "are logically private [thinkable only by one thinker]. But this does not imply that such propositional contents are intersubjectively inaccessible" because we can easily identify such thoughts (Künne 1997, 57).
} 
The Unshareability View as a default and perhaps compulsory reading of Frege's legacy on self-thought has also permeated ranks somewhat less bound to the strictures of Fregeanism. In these ranks too, versions of the Unshareability View are both attributed to Frege and endorsed. Richard Heck, for instance, accepts that the "self-conscious Thought that I am a philosopher is one that only I can entertain: at least, it is the self-conscious Thought that $I$ am a philosopher only when I entertain it" (Heck 2002, 10, emphasis his). What Heck believes is wrong with this conception is precisely not the unshareability of self-thought, but a naive conception of communication understood as requiring shareability of thought. A commitment to the Unshareability View that requires us to move away from naive conceptions of communication issues also in the work of philosophers sympathising with, although perhaps not seeing themselves as part of, a strict Fregean tradition (e.g. Chalmers 2011; Davies 1982; Higginbotham 2003; Morgan 2009).

However, the overarching impact of the Unshareability View is perhaps most tellingly illustrated through the work of critics of Frege who do not commit themselves to, and even overtly oppose, a Fregean stance. These scholars not only lay stress on Frege's guiding commitment to unshareable self-thought but, what is more, put forward alternative analyses that can be seen as, as it were, non-Fregean variations of the Unshareability View. John Perry's above-mentioned developments on Frege are a case in point. As is known, Perry's alternative to the Fregean framework involves a full endorsement of a "metaphysically benign form of limited accessibility", according to which, access to selfthought by certain (first-personal) ways or belief states is restricted to the self-referring subject (cf. Perry 1979, 19, see also Perry 2012, García-Carpintero 2016).

Saul Kripke is another representative example. While defending his acquaintancebased interpretation of sense, he points out that "Frege does not think that the very same [first person] thought can be expressed by anyone else" (Kripke 2008, 212, emphasis his) and, that Frege "always held that certain thoughts were incommunicable" (Kripke 2008, 213). But Kripke seems also to take the Unshareability View to be abundantly obvious: "One need not be a rigid follower of Descartes to see that indeed each of us is acquainted with her/himself in a special first person way. There is nothing mysterious about this" (Kripke 2008, 214).

More cautiously, but still explicitly, Tyler Burge sees "Frege's claim about the unshareability of certain particular senses" to be "consistent with the rest of his philosophy" and, in line with his own views, as "further ground for not identifying [Frege's] conception of sense with a conception of communal linguistic meaning" (Burge 2005, 38, fn. 32; see also Burge 1979). Other non-Fregean authors that explicitly bow to the Unshareability View as an interpretation of Frege and, in fact, as a mark of their own approaches to self-thought, include Scott Soames (2015) or François Recanati (2017), among others.

In sum, it is hard to overestimate the importance of the Unshareability View as a common denominator of many otherwise disparate renderings of Frege and a privileged standpoint on self-thought set against the backdrop of Fregean theory. The list of examples bolstering the Unshareability View in the discussion of Frege-imbued conceptions of self-thought could certainly be enlarged. While I shall discuss several exceptions to this general trend in the next sections, it seems fair to conclude that the Unshareability View is by far the preferred interpretation of Frege's legacy regarding self-thought among Fregean and non-Fregean circles alike, and indeed the received Fregean position on this score. 


\section{Fregean Self-Thought}

In spite of the just highlighted line of thought, it is far from obvious that the Unshareability View should be anything like the default standpoint when considering the Fregean take on self-thought. This is so even if we focus on Frege's passage in Thoughts quoted above. There is no doubt that the passage endorses the existence of unshareable distinctive ways of thinking of a subject. However, the conclusion that self-thought is itself unshareable can only be reached on the assumption that selfthought is only thinkable through unshareable distinctive ways. This is a view that is explicitly denied in Thoughts. Frege's very next sentence after intoning 'special and primitive' ways of thinking about oneself is that Lauben "may want to communicate with others" and "cannot communicate a thought he alone can grasp." From this, Frege concludes that he "must use 'I' in a sense which can be grasped by others, perhaps in the sense of "he who is speaking to you at this moment'" (Frege 1984, 359-360). Many have pointed out the implausibility of Frege's tentative suggestion-what Dummett termed "the 'I' of communication" - as a satisfactory characterisation of self-thought (Dummett 1981, Chap. 6; Kaplan 1977). Even if we admit this, however, Frege's suggestion indisputably reveals from the outset that primitive and special ways associated with the first person pronoun are not on a par with thoughts expressed therewith, at least not if among these we are to find properly communicable thoughts.

The grounds for the Unshareability View as the most plausible interpretation of Frege's understanding of self-thought grow even fainter once we note that Thoughts also contains the claim that one may express the same thought as someone else would by uttering the first person pronoun. In particular, Lauben's thought expressed with an utterance of "I was wounded" may also be expressed by Leo Peter when uttering "Dr. Gustav Lauben was wounded" (Frege 1984, 358). On the assumption that one can only express thoughts one can think, Frege's observation brings out the possibility of thinking a kind of shareable thought expressible with 'I' or thinking self-thoughts other than in an unshareable way. It is therefore not surprising that Frege is also unambiguously clear in Thoughts on his refusal of thoughts that are private and have "this owner alone" (Frege 1984, 362). The reason for this refusal is, of course, Frege's flagship distinction between thought - and presumably self-thought - and private ideas.

Although Thoughts is certainly the most authoritative of Frege's works on indexicals and self-thought, critics have also pointed out that the views in Thoughts agree with Frege's other prominent discussion of the topic in his unpublished Logic of 1897. Two decades before the publication of Thoughts, Frege endorsed without qualification the claim that self-thought can be expressed with the use of a proper name: "It is not necessary that the person who feels cold should himself give utterance to the thought that he feels cold. Another person can do this by using a name to designate the one who feels cold" (Frege 1979, 134-135). This too contradicts the claim that only special and primitive ways are involved in the expression and thinking of self-thought.

These points are not new. ${ }^{4}$ I only rehearse them here to make clear that, pace Perry, Evans, and many others, there is no straightforward interpretation of Frege's considerably succinct remarks on self-thought that obliges us to admit unshareable self-thought. Indeed, unless one wishes to attribute to Frege persistently inconsistent or convoluted

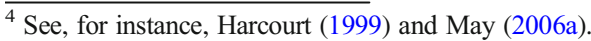


views, one should not rush to conclude from the quote in Thoughts that primitive and special ways of thinking are necessary for thinkability or grasp of self-thought. ${ }^{5}$ For shareability is a Fregean condition on thought par excellence-as vigorously flagged, for instance, in On Sense and Meaning (1984, 160-161) - and nowhere does he explicitly concede that self-thought is an exception to this condition.

The allure of the Unshareability View must be grounded, therefore, in considerations other than Fregean exegesis. It must lay, most plausibly, in the idea that shareable selfthought leads to unbearable tensions with respect to other central Fregean theses, whether or not Frege himself ever realised this. We may thus consider three claims whose combination seems, at first blush, to ipso-facto exclude shareability of first person thought:

(Distinctive Cognitive Value-DCV)

Self-thought is individuated in terms of cognitive value - as opposed to reference.

(Special and Primitive Ways-SPW)

Self-thought involves a special and primitive way of thinking of a self.

(Full Determination of Reference-FDR)

Self-thought fully determines reference to a self. ${ }^{6}$

We may call the combination of the foregoing theses - viz. DCV, SPW and FDR the Strict Fregean View of self-thought. ${ }^{7}$ The bulk of the reasoning supporting the Unshareability View is therefore as follows: One cannot endorse the confederation of theses corresponding to the Strict Fregean View and also accept shareability of selfthought. But is this line of reasoning correct?

A first thing to note is that DCV, which takes the cognitive value of self-thought as individuating that thought, is the only claim of the triad that directly displays a necessary condition on possession or thinkability of thought. Cognitive value is paradigmatically uncovered via Frege tests: situations in which rational judgemental dispositions towards thoughts relevantly differ. This is what Evans articulated in terms of the 'Intuitive Criterion of Difference' for the individuation of thoughts: If a rational subject may accept a thought $\mathrm{T}$ but remain agnostic or refuse another thought $\mathrm{T}$ ', then $\mathrm{T}$ and T' exhibit different cognitive values and are therefore, by Fregean lights, distinct thoughts (Evans 1982, 18-22).

It is rather obvious, however, that DCV cannot by itself ground unshareability, at least not if the Intuitive Criterion of Difference is our preferred measure of cognitive value. This is so for the simple reason that, if there is unshareability of self-thought, there will be, in actual fact, no possible scenario in which one and the same subject accepts a self-thought but rejects or is agnostic about a distinct self-thought belonging to some other subject. Provided that to reject or be agnostic

\footnotetext{
${ }^{5}$ Some authors do see, however, inconsistency in Frege's views (e.g. Geach 1977, viii; Dummett 1981, 118124).

${ }^{6}$ See above for Frege's statement of SPW. Formulations of DCV occur for instance in On Sense and Meaning (1984, 162), Function and Concept (1984, 145) or A Brief Survey of My Logical Doctrines (1979, 197-198). FDR implies complete or absolute senses - see e.g. Thoughts (1984, 370), and specifically in the context of the first person, Logic (1979, 134-135).

7 Together with SPW, versions of DCV and FDR are beaconed in other discussions of Fregean self-thought (e.g. Evans 1981, §2; Peacocke 1981, 188-189; Perry 1979, 5-6). To keep this discussion focused, I shall confine attention to the Strict Fregean View so characterised on the assumption that it captures the core of Frege's views on self-thought, and leave it open whether other claims or considerations could be added for the purposes of a complete exegetical account.
} 
about $\mathrm{p}$ requires entertaining $\mathrm{p}$, unshareability very neatly entails that there cannot be applications of the Intuitive Criterion of Difference yielding a difference between self-thoughts entertained by different people. ${ }^{8}$

The combination of DCV and SPW does not suffice to get unshareability either. As Colin McGinn observes (McGinn 1983, Chap. 5), there is a quantificational reading available to the Fregean quote in which "everyone is presented to himself in a special and primitive way, in which he is presented to no one else" lays out an existential quantification over a special and primitive way of thinking that is universally predicated of subjects - as opposed to a universal quantification over subjects that existentially predicates, of each of them, a special and primitive way of thinking. On this reading, two distinct subjects may possibly use the same special and primitive way $w$ of thinking about a self. There is thus no conceptual difficulty in taking thought-defining cognitive value and special and primitive ways to go together in ways that are invariant from subject to subject.

It is DCV, SPW and FDR, taken together, what seems to force us to accept the Unshareability View. If every subject signals a distinct candidate reference for a given self-thought, and self-thought fully determines reference (by FDR), then every subject must also signal, not merely a distinct candidate reference, but a distinct reference-determining self-thought. One might think that distinct reference-determining self-thoughts can still be shared even if self-thought is individuated at the level of cognitive value (by DCV) - if, for instance, subjects themselves can, in context, be part of an invariant reference-determining selfthought. However, since, on the present account, reference-determining selfthought is characterised at the level of cognitive value (by DCV) and involves a special and primitive way of thinking of a subject accessible only to that subject (by SPW), thinkability of self-thought must itself be subject-specific, that is to say, intrinsically tied to each particular candidate reference of self-thought. As a result, subject to subject shareability is out of view. This looks like a decisive result against shareability. For DCV, SPW and FDR are presumably the building blocks of Frege's take on self-thought-the Strict Fregean View as I call it. The Unshareability View would seem to reemerge therefore through the consideration of Fregean claims even if the exegesis of Frege's writings is contentious. The argument, laid out in full, is thus as follows:

1. For every distinct self-thought, there is a distinct cognitive value. (by DCV)

2. For every self, there is a special and primitive way of thinking of that self. (by SPW)

3. For every self, there is a distinct self-thought referring to that self. (by FDR)

Conclusion: For every self, there is a special and primitive self-thought referring to that self. (by 1,2 and 3)-The Unshareability View

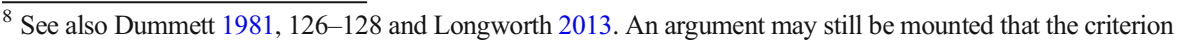
will deliver a relevant difference for one subject between self-thoughts - expressible with 'I' - and those thoughts arguably shared by others - expressible with other terms such as 'you'. However, note that such an argument would require, beyond the criterion, substantial assumptions about (i) what the shareable thoughts (and their means of expression) actually are, and (ii) how the intrapersonal and interpersonal cases are related. It seems thus correct to conclude that there is no direct argument from DCV (and the criterion) to the Unshareability View. I shall return to Evans's criterion in Section 4.
} 
Note, however, that the pivotal role of (2) in driving the argument to the Unshareability View relies on a thus far implicit assumption:

(Assumption)

Ways of thinking stand in a one-to-one correspondence with (or just are) cognitive values.

Without this assumption, one cannot grant that the special and primitive way of thinking about a self in (2) yields - in combination with DCV and FDR - a cognitive value individuating a special and primitive self-thought referring to that self. The assumption may be disputed as an interpretation of Frege. It is, I suggest, squarely unwarranted as a willy-nilly reading of the Fregean claims about self-thought. If we cease to identify cognitive value and way of thinking when considering self-thought, shareability is potentially back into the picture. In the next Section 3, I shall take up this line and argue that one may, in fact, respect the Strict Fregean View while still endorsing the shareability of self-thought.

\section{In Defence of Shareability}

What we need in order to make full sense of the possibility of shareable self-thought within the Strict Fregean View is, therefore, a notion of way of thinking or mode of presentation that does not involve a one-to-one correspondence with thoughtindividuating cognitive value. We may conceive of ways of thinking or modes of presentation as being an element of but not identical with cognitive values. This is indeed the suggestion that ensues from Frege's early remark in On Sense and Meaning to the effect that the sense (of a sign) is "wherein the mode of presentation is contained" (Frege 1984, 158). A candidate to meet this notion is what I have elsewhere called 'perspectives' (Verdejo forthcoming, 2017a). Perspectives are a kind of way of thinking or mode of presentation of a reference associated with a type of concept or thought. According to this proposal, a type of concept or thought may bear a one-to-many relationship to their associated perspectives.

In order to fix ideas, consider, if we may, your favourite dish and its associated thought type, say, the cannelloni-thought type. There are several perceptual ways in which this dish might be presented to you and hence, arguably, several ways or modes by which the dish might figure in your thoughts. To a first approximation, the modes in question can be characterised in terms of perceptual information. For instance, the dish might be present to you in thought via vision, smell or indeed taste information. These modes of presentation are, in a clear sense, about the cannelloni dish itself and very much not about the thought-type in question. Interestingly, each of these modes of presentation need not require the others to intervene. Nor would they seem to comprise, separately, what it is for you or what necessary condition you have to meet to actually think the cannelloni-thought type. For indeed you might think that thought type without one, two or-if, say, you happen to know about the dish by testimony-perhaps any of those perceptual modes of presentation actually intervening.

In a similar vein, self-thought can be seen as involving several perspectives or modes of presentation that do not require other perspectives to intervene. The perspectives do not, or do not separately, individuate or yield a necessary condition for the thinkability of self-thought. Also, like the perceptual modes of presentation associated 
with the cannelloni-thought type, the perspectives might be conceived as characterised in terms of information of a reference - namely, a particular subject - and not information of the self-thought type itself. The overall picture is completed, at this initial state, if we identify one of the perspectives crucially at play in thinking self-thoughtwhat we may dub the 'first person perspective' - as the special and primitive mode of presentation that at most one subject can have on him or herself.

On this account, self-thought (and perhaps other types of thought) may have a number of perspectives associated with it. While corresponding to one and the same thought, each perspective displays a characteristic informative relation toward a given reference. When ways of thinking or modes of presentation are understood as perspectives, we begin to see how all the insights of the Strict Fregean View can be retained without a commitment to subject-to-subject unshareability. Since thought-individuating cognitive values bear a one-to-many relation to perspectives, the existence of special and subject-specific perspectives does not entail the existence of special and subjectspecific thought-individuating cognitive values. Differing perspectives may thus make available one and the same self-thought with the same subject as a reference. We may flesh out this possibility more accurately by making space for a more detailed analysis of the conditions for the instantiation of the self-thought type and its associated perspectives.

The self-thought type, or self for short, is the type of thought used in thinking about subjects via indexicals. Let us call $E$ the event of thinking actually undergone by the agent $x$, when $x$ uses self to refer to $x$. In what is a variation of Christopher Peacocke's ideas, we may consider self as being individuated by the fact that the condition for something to be its reference is that it be the thinker of $E$ (see also Verdejo forthcoming, 2017a, 334-335). This simple characterisation allows us to consider different perspectives potentially operative in the instantiation of self. When the event of thinking undergone by a thinker instantiating the type is actually $E$, then the thinker typically draws on this information and hence exploits the first person perspective. Other perspectives, such as the third or second person perspectives, will be typically active whenever the event of thinking undergone by the thinker is distinct from $E$-perhaps together with some other condition. It follows from this that self as applied to $x$ might be entertained or accessed to by indefinitely many thinkers other than $x$ even though only $x$ can exploit the first person perspective to so refer to $x$.

The take-home point for present purposes is that, when modes of presentations are conceived as perspectives, self-thought can be associated with and accessed to from different perspectives, such as the first person and the third person perspective. With this theoretical reconstruction, we can keep hold of all the essential theses highlighted in the Strict Fregean View while ducking unshareability. First, self-thought can be taken to involve a distinctive or thought-individuating cognitive value (by DCV) as spelled out in the analysis above. The distinctive cognitive value ensues from the condition for something to be the reference of the concept which displays different perspectives

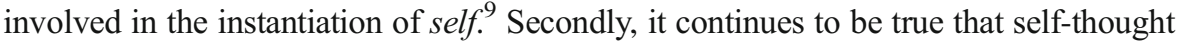
involves a special and primitive way of thinking of a self. We can identify this way with

\footnotetext{
${ }^{9}$ As hinted above, and as we will see in some detail below (Section 4), perspectives - such as the first and third person perspective-plausibly involve distinctive intensionally specified information on which the subject draws in instantiating self.
} 
one particular perspective, namely, the first person perspective or the perspective typically operative when the thinker is the very referent of the thought (in line with SPW). We may also concede that this perspective is not shareable. Unlike what proponents of the Unshareability View maintain, however, the first person perspective is not all there is to the individuation of self-thought. Other perspectives can now also come into play in order to secure shareability: The same self-thought is accessible, for instance, from the third person perspective-i.e. when thinkers are distinct from the reference of self. Finally, we can impeccably respect the principle that self-thought determines reference (by FDR). Whenever a self-thought varies in reference, a distinct relevant type of thought is at stake. Thus, although anyone can entertain the same selfthought as I entertain when I am thinking about myself from the first person perspective - say, by thinking about $m e$ from the third person perspective - it is still true that this self-thought is of a different relevant type from the self-thought that you or I can use when thinking about you. The tripartite characterisation of the Fregean position holds sway without needing to resort to the unshareability of self-thought.

One might feel wary about the viability of the kind of framework advanced here. I shall address some central worries in the next section. Before we delve into them, however, it is worth to briefly pause to note that, although relatively simple, the proposal that emerges from the above considerations is more rightfully called 'Fregean' than others which, while adopting the shareability of self-thought within a Fregean stance, efface one or more of the theses constituting the Strict Fregean View. To substantiate this point, I shall in what follows briefly tackle three possible alternative strategies for an articulation of shareability that would seem to exhaust the options available for a Fregean theorist at this point.

A first strategy consists of defending shareability by directly equating self-thought with the thought other subjects can express and think. One seems to find versions of this strategy in the work of Rödl (2007, Chap. 6) and Travis (2013, Chap. 9). According to Rödl, for instance, uses of the first person and second person constitute exercises of the same power or act of thinking, and therefore express the same thought: "As 'You...' said by me to you and 'I...' said by you in taking up my address, express the same act of thinking, they express the same thought" (Rödl 2007, 197, emphasis his). While this line of argument might be said to hold on to FDR, it clearly fails to live up to DCV and SPW. I shall discuss the failure to respect DCV in ways that also apply to this strategy below. As for SPW, and assuming that the customary one-to-one correspondence between ways of thinking and thought-individuating cognitive values holds, it seems clear that if the thought expressed with 'I' by a subject is just the same as the thought expressed with another term - such as 'you' - by someone else no special and primitive way of thinking of a subject can be in view (explicit refusals of SPW are found, e.g. in Rödl 2007, 194-197 and Travis 2013, 274-278).

A second, more frequented alternative proposes to restrict the shareability of selfthought to certain contexts or cases. Insofar as shareability is retained in such contexts or cases, this strategy also loses sight of SPW and, arguably too, DCV. For instance, José Luis Bermúdez sets out a framework in which self-thought is bound to respect the so-called Symmetry Constraint (Bermúdez 2005, 2017, Chap. 4) so that we "allow tokens of 'I' to have the same sense as tokens of other personal pronouns such as 'you' in appropriate contexts" (Bermúdez 2017, 70). Versions of contextually restricted shareability of self-thought are found also in the works of Guy Longworth and Edward 
Harcourt. On Longworth's view, for instance, exercises of 'I'/'you' capacities would involve (grasp or expression of) the same thought "only in cases in which those exercises are connected as sub-capacities in an episodic capacity that is shared amongst the possessors of the subcapacities" (Longworth 2013, 78). From a different angle, Harcourt advances an interpretation of Frege in which the linguistic function of indexicals - including ' $\mathrm{I}$ ' - is to "serve as it were as a blank screen onto which senses are projected by those who hear them" (Harcourt 1999, 339). The shareability of selfthought is preserved, on this rendering, when different subjects happen to use different terms to capture (or project) the same sense or thought in a context. ${ }^{10}$

That this cluster of views dispenses with SPW seems clear at least in the contexts in which shareability is proclaimed. For insofar as interpersonal shareability holds, and ways of thinking univocally correspond, as usual, to thought-individuating cognitive values, there is no room in such contexts for special and primitive ways of thinking attributable to a subject to play their part. Unsurprisingly then, one finds special and primitive ways of thinking acutely left off the list of principles that Bermúdez's approach is devoted to conform to (Bermúdez 2017, Chap. 6). These include, however, a principle along the lines of FDR - what he terms 'Truth Conditions' - and DCVreferred to as 'Frege's Criterion'. By contrast, Bermúdez cites Frege's 'special and primitive ways' in Thoughts as supporting the claim that '[f] or Frege, the sense of 'I' is private and unshareable" (Bermúdez 2017, 61) —something that Bermúdez's account is very well designed to defuse.

But note, more tellingly, that if — as this family of approaches suggests — we allow terms displaying distinct ways of thinking to express the same thought 'in appropriate contexts', and ways of thinking are again on a par with cognitive values, we seem to blur or weaken the sense in which cognitive value actually individuates thought. In such 'appropriate contexts', only one way of thinking can be allowed for one cognitive value individuating one shareable thought. But it seems hard to reconcile this result with the fact that 'I' and 'you' do display different ways of thinking even when referring to the same subject and also must therefore indicate distinct cognitive values and thoughts. This is shown for instance when I inadvertently see myself in a mirror and believe "I am a philosopher" but reject, while hastily looking at my reflection, "You are a philosopher". Thus, the contextual sameness of thought brought out by these views arguably clashes also with DCV. The situation is only made worse, of course, when shareability is contextually unconstrained - as the first strategy examined above would have it.

In short, cognitive distinctiveness is blurred, if not erased, as a requisite for the individuation of thoughts if context can make it possible for expressions standardly differing in way of thinking to express the same thought. ${ }^{11}$ This would be a central - and perhaps unsurmountable - problem for shareability stances were it not possible to detach ways of thinking from cognitive values along the lines of the foregoing proposal. If, by contrast, two (or more) ways of thinking can

\footnotetext{
${ }^{10}$ In these authors' work, the idea of contextually constrained shareability also naturally links up with the view that uses of 'I'/'you' may involve the expression of more than one type of thought (Longworth 2014, §5; Harcourt 1999, §4). Note, however, that to suggest that shareable and unshareable types of thought may be expressed by these terms would do nothing to shun the problems pointed out in the main text regarding the elucidation of shareable thought.

${ }^{11}$ See Harcourt 1999, §7-11 for a similar diagnosis with the discussion of alternatives.
} 
correspond to one and the same thought-individuating cognitive value, we make space for recognising the difference in ways of thinking expressible with 'I' and 'you' while also retaining the shareability of self-thought independently of context. I shall return to this point below. ${ }^{12}$

The third and last strategy for garnering shareability resorts to a notion of subject-to-subject invariant sense. Robert May (2006a, b) has probably advanced the most elaborate articulation of this notion as an interpretation of Frege. He draws the distinction between senses that determine or present reference and senses that (merely) constrain reference. When sense constrains reference, as in the case of self-thought, it is a subject-to-subject invariant sense which provides a reference in a context (May 2006a, 502-503). This view does leave room for the consideration of different ways in which a reference is present depending on the type of indexical at stake - such as 'I' or 'you'. Unlike perspectives, however, such ways of thinking are not derivable from (a reference condition for) self-thought and do not play a role in understanding. Consequently, although the speaker expresses an indexical or demonstrative thought "with respect to the way in which the reference of the indexical or demonstrative is present to him", in grasping this thought, the hearer "need not grasp the particular way in which the reference is present to the speaker", nor does the speaker need to "make any assumptions as to the particular way [the reference] is present to the hearer" (May 2006a, 509-510, emphasis his). More importantly, since they are invariant from subject to subject, thoughts expressed with indexicals are not complete and are, therefore, "not distinguishable de dicto, but only de re. To distinguish them, we must transition to the res that the beliefs are about" (May 2006a, 514). In sum, even if this view were still to keep hold of a notion of way of thinking that preserves SPW and DCV for a shareable kind of self-thought, it is clearly forced to rule out FDR by invoking invariant but incomplete senses that only constrain reference.

The foregoing discussion does not do justice to the richness of all these disparate inquiries, nor does it adequately reflect the important points of agreement with the view defended here. All the same, their consideration acutely illustrates (i) the dominant impression, firmly rooted even among its advocates, that the shareability of self-thought would require a greater departure from the Strict Fregean View than in fact needed, and (ii) the significance of the view defended here in the light of other leading accounts found in the literature. ${ }^{13}$

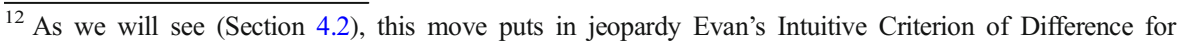
thoughts. It is open for theorists initially belonging with the first and second strategies to accept and also invoke the distinction between way of thinking and cognitive value in order to eventually respect DCV and SPW. If they did, they would need to spell out the distinction and acknowledge the full complexity of the notion of cognitive value for self-thought in ways that would draw them very close to the kind of account I am setting forth here in terms of perspectives.

${ }^{13}$ An exception to the shareability-strategies just surveyed is Lukas Skiba (2017), who has proposed a framework very germane to the one outlined here in which unshareable ways of thinking (or 'senses' in his terminology) combine with shareable self-thought. Since he is mainly concerned with thought composition and the problem of unthinkable thoughts, however, he does not explicitly articulate his position as endorsing all the elements of the Strict Fregean View, nor does he offer a specific account of self-thought as I am attempting to do here.
} 


\section{Shareability and Cognitive Value}

I take the preceding to establish that, independently of what Frege's own view really was, there is no combination of distinctive Fregean claims about self-thought that forces us to endorse the Unshareability View. There are however other considerations that would seem to put pressure on the very possibility of shareable self-thought on the proposed account. If sound, these considerations may turn an initially plausible idea into one fraught with difficulties around the corner. Three hurdles of increasing concern stand out. They all bring out worries about the explanatory power of perspectives regarding the proper fleshing out of Distinctive Cognitive Value (DCV) and the cognitive effects associated with self-thought. I certainly do not have the space here to offer a complete account of the issues from which these worries emanate. The purpose of this partially speculative section is rather to show that, when properly construed, the perspective-based account of self-thought - just as perhaps other Fregean accounts of shareability - is both free from obvious insuperable difficulties and suggestive of promising avenues for new research.

\subsection{Iterated Frege's Puzzles}

It is one of the most celebrated merits of thought constructed at the level of sense or cognitive value - as opposed to reference - that it provides an apt solution to Frege's puzzles as they arise, more precisely, in the context of propositional attitude reports. This solution is, though by no means incontestable, one of the main reasons fuelling the endorsement of DCV. Thus, since Frege's pioneering considerations in On Sense and Meaning, many philosophers agree that cognitive value can be invoked to explain why reports of the form "S believes that $a$ is F" and "S believes that $b$ is F" might have differing truth values even if $a$ and $b$ denote the same object and are substitutable salva veritate in the that-clauses. However, if we are to allow anything like the view proposed in the previous section, it would seem that Frege's puzzles come back into the picture through the rear door. For these puzzles, it would seem, can be replicated at the level of perspectives themselves.

Consider Boris, Theresa and Donald. Let us suppose that Boris has a certain schizoaffective personality disorder that eventually affects his capacity to refer to himself under the first person perspective. Theresa knows about Boris's disease but she knows very little about Donald and, in particular, has no reason to believe that Donald has any such mental condition. In this scenario, (1) is certainly false, but (2) and (3) are true:

(1) Theresa believes that Boris believes that he himself is alive.

(2) Theresa believes that Boris believes that he is alive.

(3) Theresa believes that Donald believes that he himself is alive.

As it happens, Theresa is oblivious to the fact that 'Donald' and 'Boris' designate the same person. Note that, since the proposed account endorses sameness of thought for first and third person perspectives or ways of thinking of a subject, (1), (2) and (3) must concern the same self-thought attributed to one subject-i.e. Boris/Donald-in the embedded that-clause. How can we, thus, explain the potential difference in truth value between (1), on the one hand, and (2) and (3), on the other hand? 
To answer this question, we need to advert to the fact that, on the recommended construal, belief reports are sensitive to perspectives. By the use of the emphatic reflexive or quasi-indexical 'he himself', (1) and (3) pick out one and the same perspective, namely, the first person perspective, whereas (2) picks out the third person perspective. Furthermore, and importantly, perspectives associated with self-thought, just as thoughts themselves on a Fregean framework, need not be individuated extensionally - i.e. by means of a specification of the reference and the thinker at stake - but intensionally - i.e. in terms of the information associated with a way of thinking of that reference by the thinker. The differing truth value of (1) and (3) can be seen therefore as a consequence of the fact that the featuring reports attribute both a self-thought and the first person perspective, that is to say, the perspective involving the information that the subject (Boris or Donald) is the thinker of the thought in question. While Theresa is keen to attribute this perspective to Donald, she would refuse to do so in the case of Boris in spite of the fact that Donald is Boris. This explains the differing truth values between (1) and (3). The truth of (2) is similarly explained because Theresa believes that Boris is very well capable of entertaining a self-thought that has him as a reference under the third person perspective which, roughly, draws on the information that Boris is a thinker but not necessarily the thinker of the thought in question.

In sum, when perspective-individuating ways of thinking are correctly construed they can be elucidated in terms of intensionally specified information, such as the information that a given subject is the thinker of a certain event of thinking. Iterated puzzles are arrested because attributions of self-thought in a context can be interpreted as involving the attribution of a cognitively relevant perspective along with the relevant self-thought.

\subsection{Intuitive Criterion of Difference}

Even if one agrees that perspectives are not problematic from the point of view of iterated Frege's puzzles, one might still cast further doubts on the compatibility of perspectives and thought-individuating cognitive value. More precisely, the worry may concern whether self-thought so interpreted can live up to Evans's Intuitive Criterion of Difference. According to this noted criterion, two thoughts, $\mathrm{T}$ and $\mathrm{T}$ ', are distinct if a rational subject can accept $\mathrm{T}$ and not accept or be indifferent toward $\mathrm{T}$ ' (see also Section 2). The criterion is characteristically Fregean and indeed, as suggested above, one of the most well-known ways of fleshing out the idea that self-thought is framed in terms of DCV. However, is the perspective-based account of self-thought compatible with the Intuitive Criterion of Difference?

As noted above, there is no possible scenario in which the Intuitive Criterion of Difference would yield a relevant intersubjective difference between thinkers of self-thoughts on the assumption that they are not shareable from subject to subject. That said, it is indeed easy to mount a case in which the Intuitive Criterion of Difference is violated if the here recommended approach is taken at face value. Consider, to retrieve an earlier example, two co-referring thoughts expressible using the first and second person pronouns such as "I am a philosopher" and "You are a philosopher". It is certainly conceivable that I may utter these sentences to express thoughts towards which I exhibit differing attitudes. For instance, I may see my reflection in a mirror and believe the thought expressed by "I am a 
philosopher" but forcefully reject the thought expressed by "You are a philosopher". If the Intuitive Criterion of Difference is operative, we have to conclude that these thoughts, and in general, thoughts expressible with the first person pronoun are distinct from thoughts expressible with the second person pronoun. By contrast, it is a consequence of the account proposed in this paper that the target 'I'- and 'you'-thoughts may be counted, and in indefinitely many cases will be counted, as expressing different perspectives attached to the same self-thought.

While it must be acknowledged head on that violations of the Intuitive Criterion of Difference are allowed in the recommended framework, it is also crucial to distinguish violations of the Intuitive Criterion as such from transgressions of the view that selfthought is individuated in terms of a distinctive or individuating cognitive value - the thesis referred to here as DCV. More precisely, one can acknowledge violations of the Intuitive Criterion and still claim that it is the combination of the cognitive effect of various perspectives - as captured in the condition for something to be the reference of the thought - what comprises the kind of cognitive value that individuates self-thought, without thereby committing oneself to the view that every difference found in accordance with the Intuitive Criterion amounts ipso-facto to a difference in the type of thought. In other words, DCV requires us to associate a thought-individuating cognitive value, however complex, with self-thought but it does not require us to associate a thought-individuating way of thinking with that thought. On this account, the thoughtindividuating cognitive value associated with self-thought may consist of the one manifested by the whole arrange of subject-referring indexical expressions - such as 'I', 'you' or 'he' and 'she'. Thus, although the shareability of self-thought as articulated here forces us to reject the Intuitive Criterion for self-thought, and also presumably for other sorts of thought expressible through indexicals, it does not force us to reject the chief Fregean claim that there is a distinctive cognitive value associated with selfthought.

The target violations of the Intuitive Criterion are not only harmless from the point of view of DCV. In addition, they may in fact allow for the possibility of what is often called 'cognitive dynamics' in the case of self-thought. The idea of cognitive dynamics, set forth by David Kaplan (cf. Kaplan 1977, 537-538, fn. 64) and traceable back to Frege's own writings, has often been dissociated from selfthought. ${ }^{14}$ To a first approximation, cognitive dynamics refers to the capacity of a thinker to keep track of thoughts - paradigmatically expressed by indexicalsacross several contexts that display disparate ways of thinking. Since perspectives withdraw the one-to-one correspondence between ways of thinking and types of thought, they also make space for the possibility of getting hold of the same selfthought dynamically across a range of situations in which different perspectives or ways of thinking are operative. While this is admittedly little more than a gesture towards an account of cognitive dynamics for self-thought, perspectives may plausibly contribute to one by invoking self-thought perspectives that converge on one and the same subject and are exploited by different people while retaining the fundamental tenets of the Strict Fregean View.

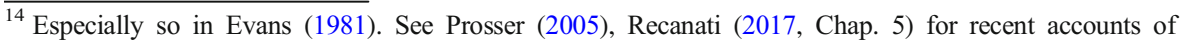
cognitive dynamics.
} 


\subsection{Self-Thinking, Self-Knowing and Self-Acting}

Fregeans are concerned with offering an individuation of thought at the level of cognitive value quite beyond Frege's puzzles and the Intuitive Criterion. Two capital explanatory targets emerge, most remarkably, when considering what Evans called the 'informational component' and the 'action component' of self-thought (Evans 1982, Chap. 7). Very roughly, the information component has to do with sources of information about the thinker that are immune to error through misidentification of the thinker in question (Shoemaker 1968), whereas the action component concerns those features of self-thought that have a direct impact on and are considered to be essential in the explanation of the thinker's behaviour (Perry 1979). Since these phenomena seem to reflect the most intimate nature of our conscious selves, the Unshareability View might seem to be the only choice available for those who seek to produce an account of these principal features and its connection with self-thought.

As J.L. Bermúdez has independently made clear (Bermúdez 2005, 2017), it is far from obvious that the Unshareability View is the only choice available in this context. There is no reason to suppose that indispensable informational or action aspects are out of view in case of shareable self-thought. On the view proposed here, there is initially no need to resort to an unshareable kind of self-thought in order to explain these phenomena even if they might require to resort to an unshareable kind of perspective or way of thinking of a self. Thus, unshareable perspectives - plausibly associated with informational sources such as introspection or autobiographical memory-may arguably be key to explaining and offering the criterion to discriminate judgments that are immune to error through misidentification and may, also, provide insights into the essential indexical elements required in the explanations of action. If so, with the aid of perspectives, Fregean self-thought may enjoy all the benefits of becoming utterly public and shareable without any obvious loss in relation to the overwhelming cognitive effects so extensively discussed by the theorists of self-thought.

An approach along the lines suggested in this article has also the potential to open the door to accounts of the informational and action component that do not undermine the public point of view on self-thought. For instance, when articulated in terms of perspectives, Fregean self-thought is certainly apt to capture the thought commonalities naturally arising from a model of communication understood as the sharing of thought (Verdejo forthcoming) but also, arguably, other intersubjective epistemic phenomena manifested in thinking of a self. With respect to action, the consideration of different perspectives over one and the same type of action-constituting self-thought allows us to make full sense of the possibility of generalisable explanations of public action (Verdejo 2017a, b) and may make way for a future elucidation of joint or collective action within a Fregean approach.

\section{Conclusion}

Can we literally share self-thoughts or first person thoughts? For many years, the Unshareability View has appeared to be the most adequate, if not the only answer for the Fregean. If the considerations put forward in this paper are on the right track, however, the credit given to the Unshareability View as the default Fregean position on 
this score has been clearly overstated. Perspectives - i.e. ways of thinking or mode of presentation associated with a type of thought that do not yield necessary conditions on thinkability - allow us to reject the Unshareability View while sticking to a Fregean research programme for the full elucidation of self-thought. In addition, and unlike other Fregean articulations of shareability, the approach advanced here has the resources to keep intact the chief claims of Frege's legacy — what I have called the Strict Fregean View. Finally, I have suggested that the consideration of perspectives do not involve any obvious or unbearable shortcoming in relation to the baseline consideration of cognitive value and is compatible with the acknowledgement of unshareable firstpersonal epistemological and behavioural phenomena. One may, in sum, aspire to an account of self-thought in which its distinctive cognitive, epistemological and behavioural features are compatible with its unrestricted shareability. There is no reason to think that one such account cannot be Fregean, and strictly so.

Acknowledgements An earlier vesion of this paper was presented the workshop Perspectival Knowledge and Experience of the Self held at University College London and organised by María José Frápolli and myself..I am deeply grateful to the audience and especially Marie Guillot, Mike Martin, Krisztina Orbán, Christopher Peacocke, Simon Prosser and Hong Yu Wong for their stimulating ideas and feedback. I also thank my colleagues at Logos Research Group (University of Barcelona) for very rewarding discussions of these issues..This research has received the generous support of the Secretary for Universities and Research of the Departament of Economy and Knowledge (Catalan Government), and also the Ministry of Economy and Competitiveness (Spanish Government) and the European Union through the research projects FFI201680588-R and FFI2015-63892-P (MINECO, AEI/FEDER, EU).

\section{Compliance with Ethical Standards}

Conflict of Interest The author declares that he has no conflict of interest.

Open Access This article is distributed under the terms of the Creative Commons Attribution 4.0 International License (http://creativecommons.org/licenses/by/4.0/), which permits unrestricted use, distribution, and reproduction in any medium, provided you give appropriate credit to the original author(s) and the source, provide a link to the Creative Commons license, and indicate if changes were made.

\section{References}

Bermúdez, J. L. (2005). Evans and the sense of "I". In J. L. Bermúdez (Ed.), Thought, reference, and experience: themes from the philosophy of Gareth Evans (pp. 164-194). Oxford: Clarendon Press.

Bermúdez, J. L. (2017). Understanding “I”. Oxford: Oxford University Press.

Burge, T. (1979). Sinning against Frege. Philosophical Review, 88, 398-432.

Burge, T. (2005). Introduction. In T. Burge (Ed.), Truth, thought, reason (pp. 1-68). Oxford: Clarendon Press. Chalmers, D. (2011). Propositions and attitude ascriptions: a Fregean account. Noûs, 45, 595-639.

Davies, M. (1982). Individuation and the semantics of demonstratives. Journal of Philosophical Logic, 11, 287-310.

Dummett, M. (1981). The interpretation of Frege's philosophy. London: Duckworth.

Evans, G. (1981). Understanding demonstratives. In H. Parret \& J. Bouveresse (Eds.), Meaning and understanding (pp. 280-304). New York: Walter De Gruyter.

Evans, G. (1982). The varieties of reference. Oxford: Oxford University Press.

Fodor, J. A. (1998). Concepts. Oxford: Clarendon Press.

Forbes, G. (1987). Indexicals and intensionality: a Fregean perspective. The Philosophical Review, 96, 3-31. 
Frege, G. (1979). In H. Hermes et al. (Eds.), Posthumous writings. Oxford: Blackwell.

Frege, G. (1984) Collected papers on mathematics, logic, and philosophy. In B. McGuinness (ed.), M. Black et al. (trans.), Blackwell, Oxford.

García-Carpintero, M. (2016). Token-reflexive presuppositions and the De se. In M. García-Carpintero \& S. Torre (Eds.), About oneself (pp. 179-199). Oxford: Oxford University Press.

Geach, P. T. (1977). Preface. In G. Frege (Ed.), Logical Investigations. New Haven, CT: Yale University Press.

Harcourt, E. (1999). Frege on "I", "now", "today" and some other linguistic devices. Synthese, 121, 329-356.

Heck, R. G. (2002). Do demonstratives have senses? Philosopher's Imprint, 2, 1-33.

Higginbotham, J. (2003). Remembering, imagining, and the first person. In A. Barber (Ed.), Epistemology of language (pp. 496-533). Oxford: Oxford University Press.

Kaplan, D. (1977). Demonstratives. In J. Almog, J. Perry, \& H. Wettstein (Eds.), Themes from Kaplan (Vol. 1989, pp. 481-563). Oxford: Oxford University Press.

Kripke, S. (2008). Frege's theory of sense and reference: some exegetical notes. Theoria, 74, 181-218.

Künne, W. (1997). First-person propositions: a Fregean account. In W. Künne, A. Newen, \& M. Anduschus (Eds.), Direct reference, indexicality, and propositional attitudes (pp. 49-68). Stanford, CA: CSLI Publications.

Longworth, G. (2013). Sharing thoughts about oneself. Proceedings of the Aristotelian Society, 113, 57-81.

Longworth, G. (2014). You and me. Philosophical Explorations, 17, 289-303.

May, R. (2006a). Frege on indexicals. The Philosophical Review, 115, 487-516.

May, R. (2006b). The invariance of sense. The Journal of Philosophy, 103, 111-144.

McDowell, J. (1984). De Re Senses. The Philosophical Quarterly, 34, $283-294$.

McGinn, C. (1983). The subjective view. Oxford: Oxford University Press.

Morgan, D. (2009). Can you think my 'I'-thoughts. The Philosophical Quarterly, 59, 68-85.

Noonan, H. (1984). Fregean thoughts. The Philosophical Quarterly, 34, 205-224.

Peacocke, C. (1981). Demonstrative thought and psychological explanation. Synthese, 49, 187-217.

Peacocke, C. (1992). A study of concepts. Oxford: Oxford University Press.

Peacocke, C. (2014). The mirror of the world. Oxford: Oxford University Press.

Perry, J. (1977). Frege on demonstratives. The Philosophical Review, 86, 474- 497.

Perry, J. (1979). The problem of the essential indexical. Nô̂s, 13, 3-21.

Perry. (2012). Thinking about the self. In J. Liu \& J. Perry (Eds.), Consciousness and the self: new essays (pp. 76-100). Cambridge: Cambridge University Press.

Prosser, S. (2005). Cognitive dynamics and indexicals. Mind \& Language, 20, 369-391.

Recanati, F. (2017). Mental files in flux. Oxford: Oxford University Press.

Rödl, S. (2007). Self-consciousness. Cambridge, MA: Harvard University Press.

Shoemaker, S. (1968). Self-reference and self-awareness. The Journal of Philosophy, 65, 555-567.

Skiba, L. (2017). Frege's unthinkable thoughts. Proceedings of the Aristotelian Society, 117, 333-343.

Soames, S. (2015). Rethinking language, mind, and meaning. Princeton, NJ: Princeton University Press. Travis, C. (2013). Perception: essays after Frege (Vol. 65, pp. 555-567). Oxford: Oxford University Press. Verdejo, V. M. (2017a). De se content and action generalisation. Philosophical Papers, 46, 315-344. Verdejo, V. M. (2017b). Explaining public action. Topoi. https://doi.org/10.1007/s11245-017-9524-2. Verdejo, V. M. (2018). On having the same first person thought. Grazer Philosophische Studien, 95, 566-587. Verdejo, V. M. (forthcoming). Thought sharing, communication and perspectives about the self. Dialectica.

Publisher's Note Springer Nature remains neutral with regard to jurisdictional claims in published maps and institutional affiliations. 